\title{
Role for insulin-like growth factor I in the regulation of electrolyte composition of uterine luminal fluid
}

\author{
S. Katagiri ${ }^{1}$, S. Ma ${ }^{2}$, B. Ho Yuen ${ }^{2}$ and Y. S. Moon ${ }^{2 *}$ \\ ${ }^{1}$ British Columbia Women's Hospital, Department of Obstetrics and Gynaecology, The University of \\ British Columbia, 4490 Oak Street, Vanconver, BC, V6H 3V5, Canada; and ${ }^{2}$ Vanconver Hospital and \\ Health Sciences Centre, Willow Pavilion, Department of Obstetrics and Gynaecology, The University of \\ British Columbia, 855 West 12th Avenue, Vancouver, BC, V5Z 1M9, Canada
}

\begin{abstract}
A potential role for insulin-like growth factor I (IGF-I) in the regulation of the uterine electrolyte environment was studied in conjunction with hyperoestrogenaemia caused by superovulation. Uterine luminal fluid from immature rats treated with 4 (control), 10, 20 and 40 iu (superovulation) pregnant mares' serum gonadotrophin (PMSG, day -2 ) and the electrolyte composition was determined on day 3 of pregnancy. Superovulation increased total cation content in uterine flushes by more than twofold, suggesting a comparable increase in the uterine luminal fluid volume. Percentages of $\mathrm{K}^{+}$and $\mathrm{HCO}_{3}{ }^{-}$content to total cations or anions increased by $27 \%$ and $16 \%$, respectively, and those of $\mathrm{Na}^{+}$and $\mathrm{Cl}^{-}$ decreased by $26 \%$ and $15 \%$, respectively, after superovulation. Daily injections with $1.0 \mu \mathrm{g}$ or more oestradiol, from day 0 to day 2, in the 4 iu PMSG-primed immature rats caused similar changes in total cation content and electrolyte composition of uterine luminal fluid. Anti-IGF-I antibody infusion in the superovulated or oestradiol-treated immature rats restored the alterations in cation composition but had no effect on anion composition and total cation content. IGF-I was infused into adult rats to achieve increased IGF-I action observed after superovulation. IGF-I infusion altered electrolyte composition, as is observed after superovulation or oestradiol treatment, but had no effect on total cation content. In conclusion, hyperoestrogenaemia caused by superovulation may alter the uterine electrolyte environment for preimplantation embryonic development. IGF-I appears to play a central role in mediating this action of oestrogen.
\end{abstract}

\section{Introduction}

Hyperoestrogenaemia caused by superovulation appears to be responsible for many detrimental effects of superovulation including early embryonic loss (Moon et al., 1990). Increased insulin-like growth factor I (IGF-I) action, caused by hyperoestrogenaemia resulting from superovulation renders the uterine environment hostile to embryonic development in rats (Katagiri et al., 1996). The same study also found that the uterine luminal fluid is no longer detrimental to embryonic development after the fluid is dialysed against conventional culture media.

Evidence suggests that the uterine electrolyte environment is under the influence of ovarian steroid hormones (Kao, 1967; Setty et al., 1973; Van Winkle et al., 1983). In general, the electrolyte environment plays a critical role in maintaining cellular homeostasis and regulating cellular metabolism. Alterations in the electrolyte composition of culture media results in retardation of embryonic development or embryonic loss (Van Winkle, 1977; Schini and Bavister, 1988; Seshagiri and Bavister, 1991; Lawitts and Biggers, 1992; Dumoulin et al., 1993). These

*Correspondence and reprint requests.

Received 28 June 1996. observations lead us to the hypothesis that alterations in the electrolyte composition of the uterine environment may be a factor that renders the uterine environment detrimental to preimplantation embryonic development.

Despite the importance of the electrolyte environment on preimplantation embryonic development, no study has attempted to determine the endocrine/paracrine regulation of the electrolyte composition of uterine luminal fluid. IGF-I is one of many growth factors that mediate the actions of ovarian steroid hormones in the uterus (Murphy and Ballejo, 1994). The present study examined a potential role for IGF-I in mediating oestrogen action on uterine electrolyte environment, in conjunction with hyperoestrogenaemia caused by superovulation. To our knowledge this is the first study demonstrating a role for growth factors in the regulation of electrolyte environment for preimplantation embryonic development.

\section{Materials and Methods}

\section{Anti-IGF-I antibody preparation}

Rabbit anti-IGF-I antiserum (Amersham Canada, Oakville, Ontario) was diluted $(1: 1 \mathrm{v} / \mathrm{v})$ with $100 \mathrm{mmol}$ phosphate 
buffer $\mathrm{l}^{-1}$ (pH 7.0) and applied to a protein A column (Bio-Rad, Mississauga, Ontario). Antibody was eluted with 1 mol acetic acid $1^{-1}$ and the eluate from the protein $A$ affinity column was then applied to a Sephadex G-25 column. The antibody solution eluted in $100 \mathrm{mmol}$ phosphate buffer $1^{-1}(\mathrm{pH} 7.4)$ was concentrated and an aliquot was subjected to protein assay (Lowry et al., 1951).

\section{Animal treatments}

All animals were purchased from the Animal Care Centre at the University of British Columbia (Vancouver, BC) and maintained at $23-25^{\circ} \mathrm{C}$ with a $14 \mathrm{~h}$ light $(05: 00-19: 00 \mathrm{~h}): 10 \mathrm{~h}$ dark daily lighting schedule. Experimental procedure was reviewed and approved by the ethical committee at the University of British Columbia.

Immature Sprague-Dawley rats were injected (i.p.) with 4 (control), 10, 20 or 40 (superovulation) iu pregnant mares' serum gonadotrophin (PMSG; Equinex, Ayerst, Montreal, PQ) in $0.2 \mathrm{ml}$ saline at 09:00 $\mathrm{h}$ at day 28 and mated overnight $60 \mathrm{~h}$ after the PMSG injection. A single injection of 4 iu PMSG in the immature rats created a normal pregnancy and thus served as the control (Nuti et al., 1975; Miller and Armstrong, 1981; Katagiri et al., 1996). A group of immature rats that had been induced to superovulate were implanted, s.c. on the back, with an Alzet osmotic pump (Model 1003D, Alza, Palo Alto, CA) at 10:00 h on day $\mathrm{I}$ (day of vaginal plug). Rats were infused (s.c.) with $1 \mathrm{mg}$ anti-IGF-I antibody $\mathrm{ml}^{-1}$ for $48 \mathrm{~h}$ at an infusion rate of $1 \mu \mathrm{h}^{-1}$.

The effect of oestrogen on electrolyte composition of uterine luminal fluid was studied by injecting (i.p.) immature rats with 4 iu PMSG in $0.2 \mathrm{ml}$ saline at 09:00 h at day 28 , followed by daily injections (s.c.) with $0.1,0.5,1.0$ or $5.0 \mu \mathrm{g}$ oestradiol (Sigma, St Louis, MO) prepared in $0.1 \mathrm{ml}$ sesame oil at 10:00 h from day 0 (day of oestrus) to day 2 of pregnancy. A group of rats given daily $5.0 \mu \mathrm{g}$ oestradiol injections was infused with anti-IGF-I antibody as above.

Adult female Sprague-Dawley rats (340-360 g body mass) were mated overnight at oestrus and infused with human recombinant (hr)-IGF-I (Sigma) from day 1 (day of vaginal plug) to day 3 of pregnancy as described by Katagiri et al. (1996). Briefly, rats were ovariectomized unilaterally on the right, via an incision made on the median line, between 10:00 $\mathrm{h}$ and 11:00 h on day 1 of pregnancy. An Alzet osmotic pump (Model 1003D) was filled with $100 \mu \mathrm{l}$ of $10 \mathrm{nmol} \mathrm{h}^{-1}$ IGF-I $\mathrm{I}^{-\mathrm{I}}$ and the distal end of the delivery tubule of the pump was introduced into the right ovarian artery proximal to the uterine artery branch. The incision in the abdominal wall and skin was sutured, leaving the pump in the abdominal cavity. Infusion was for $48 \mathrm{~h}$ at an infusion rate of $1 \mu \mathrm{h}^{-1}$. The left ovary and artery were left intact for the control. This IGF-I infusion has been shown to increase uterine IGF-I action to the same extent as that found after superovulation (Katagiri et al., 1996). The vehicle alone was infused into the control rats. Some adult rats were unilaterally ovariectomized on day 1 but not infused (non-infusion group).

Five rats were used in all groups except for the oestradiol treatment groups, where three rats were used.

\section{Collection of the uterine luminal fluids}

All the rats were killed at 11:00 h on day 3 of pregnancy and the uterine horns removed. Uterine luminal fluid was collected by flushing the uterine lumen with degassed $0.3 \mathrm{~mol}$ mannitol $\mathrm{I}^{-1}$ solution $(0.25 \mathrm{ml}$ per uterine horn $)$, within $5 \mathrm{~min}$ of being killed. The uterine flushes were kept away from air contact to avoid changes in free $\mathrm{CO}_{2}$ content. The uterine flushes were centrifuged at $3000 \mathrm{~g}$ for $10 \mathrm{~min}$ to remove cell debris. Uterine flushes from the left and right uterine horns in the same animals, injected with PMSG or oestradiol, were combined. Anion content in each supernatant was immediately determined, while an aliquot of each supernatant was saved and frozen at $-70^{\circ} \mathrm{C}$ for the cation assay.

\section{Determination of electrolyte composition}

$\mathrm{Cl}^{-}$content was determined by the coulometricamperometric method (Dietz and Bond, 1982). $\mathrm{HPO}_{4}{ }^{2-}$ and $\mathrm{HCO}_{3}{ }^{-}$contents were determined, as total inorganic phosphorus and total $\mathrm{CO}_{2}$, respectively, by using Kodak Ektachem Clinical Chemistry Slides (PHOS and $\mathrm{ECO}_{2}$, Kodak, Eastman Kodak, Rochester, NY). Frozen supernatants of uterine luminal flushes were thawed, and $15 \mathrm{mmol} \mathrm{LaCl}_{3} \mathrm{~L}^{-1}$, $4 \mathrm{mmol} \mathrm{CsCl} \mathrm{l}^{-1}$, and $100 \mathrm{mmol} \mathrm{HCl} \mathrm{l}^{-1}$ were added. $\mathrm{Na}^{+}$, $\mathrm{K}^{+}, \mathrm{Ca}^{2+}$ and $\mathrm{Mg}^{2+}$ contents were determined by atomic absorption photospectroscopy (Sanui, 1971; Sanui and Rubin, 1982).

\section{Statistical analysis}

Total cation contents of uterine luminal flushes were compared by ANOVA followed by Tukey's test using the computer software SYSTAT (SYSTAT, Inc., Evanston, IL).

\section{Results}

The concentrations of each electrolyte are presented as a percentage of the total amount of cations or anions (Figs 1-3). In the cations, the percentage of $\mathrm{Na}^{+}$in the superovulation group decreased by $26 \%$ and that of $\mathrm{K}^{+}$increased $27 \%$, as compared with those of the control group (Fig. 1). In anions, the percentage of $\mathrm{Cl}^{-}$decreased by $15 \%$ and that of $\mathrm{HCO}_{3}{ }^{-}$ increased by $16 \%$. Compositions of cations and anions in the other PMSG groups were similar to those of the non-infusion group (Figs $\mathrm{I}$ and 3). As a result, the $\mathrm{Na}^{+}: \mathrm{K}^{+}$ratio decreased from 6.0:1 (control) to 1.3:1 (superovulation) and the $\mathrm{Cl}^{-}: \mathrm{HCO}_{3}{ }^{-}$ratio from 3.6:1 to 1.6:1. Oestradiol treatment in 4 iu PMSG-treated immature rats altered the composition of cations and anions in a dose-dependent manner (Fig. 2). As oestradiol dose increased, the percentages of $\mathrm{Na}^{+}$and $\mathrm{Cl}^{-}$ decreased by $>20 \%$ and those of $\mathrm{K}^{+}$and $\mathrm{HCO}_{3}{ }^{-}$increased to the same extent. Anti-IGF-I antibody infusion restored the alterations in cations, but not anions, in the superovulation and oestradiol treatment ( 1.0 and $5.0 \mu \mathrm{g}$ ) groups to the control amounts (Figs 1 and 2). IGF-I infusion altered the electrolyte composition of the uterine luminal fluid in the infused horns but did not change that of the control horns compared with 

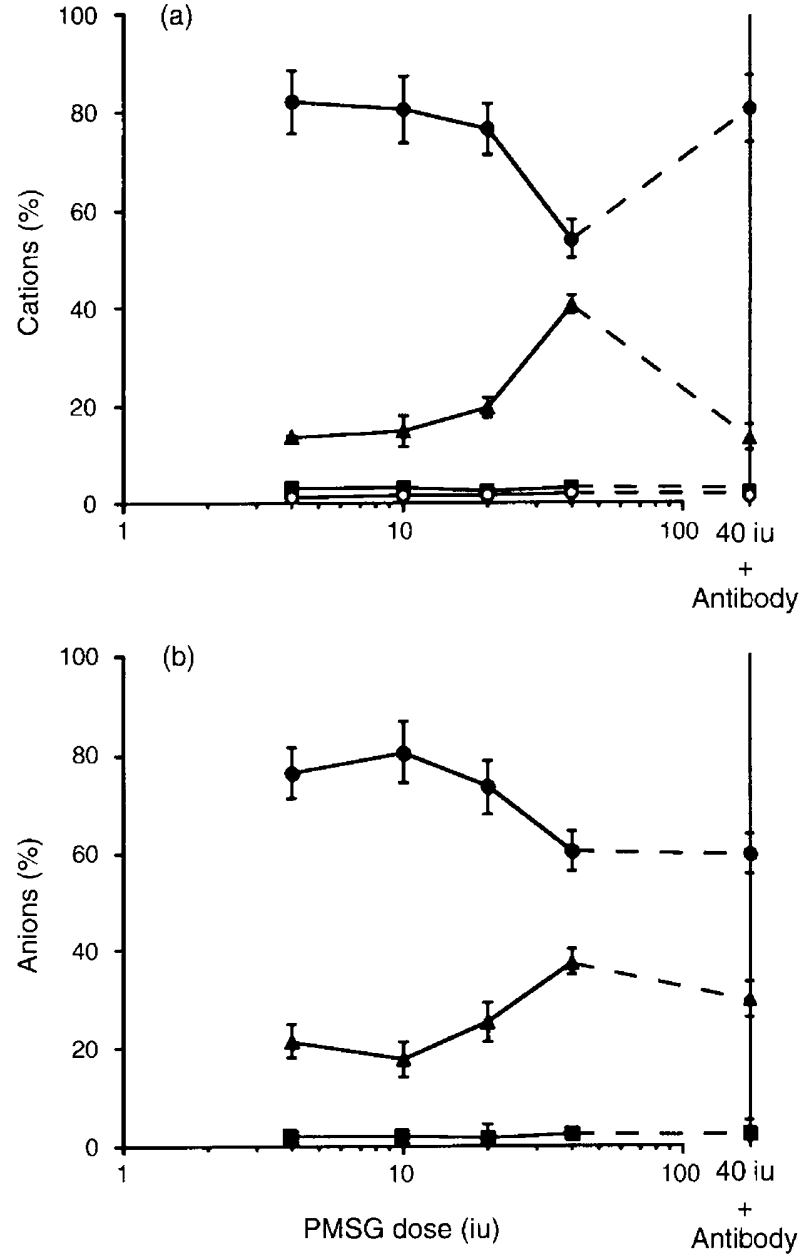

Fig. 1. The effect of pregnant mares' serum gonadotrophin (PMSG) on the electrolyte composition of uterine luminal fluid. Immature rats $(n=5)$ were injected (i.p.) with 4 (control), 10, 20, and 40 (superovulation) iu PMSG. A group of rats $(n=5)$ induced to superovulate with 40 iu PMSG was infused (s.c.) with anti-IGF-I antibody from day 1 to day 3. Uterine luminal fluid was collected on day 3 of pregnancy. The electrolyte composition is presented as a percentage of each component (the mean and $95 \%$ confidence limit) to the total (a) cations or (b) anions. (a) $\bullet \mathrm{Na}^{+} ; \mathbf{\Lambda}, \mathrm{K}^{+} ; \mathbf{\square}, \mathrm{Ca}^{2+} ; 0, \mathrm{Mg}^{2+}$. (b) $\bullet, \mathrm{Cl}^{-}$; $\Delta, \mathrm{HCO}_{3}^{-} ; \mathbf{a}, \mathrm{HPO}_{4}^{2-}$.

that of the non-infusion group (Fig. 3). The alterations in electrolyte compositions of both cations and anions in the infused horn were compatible with those observed in the superovulated or oestradiol-treated rats (Figs 1 and 2). Unilateral ovariectomy or vehicle infusion had no effect on the electrolyte composition and total cation content in the infused and control horns (Fig. 3). Total cation content in uterine luminal flushes of the superovulation and oestradiol treatment $(1.0$ and $5.0 \mu \mathrm{g}$ ) groups increased by more than twofold compared with that of the respective control group $(P<0.01$, Table 1). IGF-I infusion in adult rats and anti-IGF-I antibody infusion in the superovulated or oestradiol treated immature rats had no effect on total cation content in the uterine luminal flushes (Table 1). $\mathrm{Ca}^{2+}, \mathrm{Mg}^{2+}$ and $\mathrm{HPO}_{4}{ }^{2-}$ contents were constant throughout these experiments.
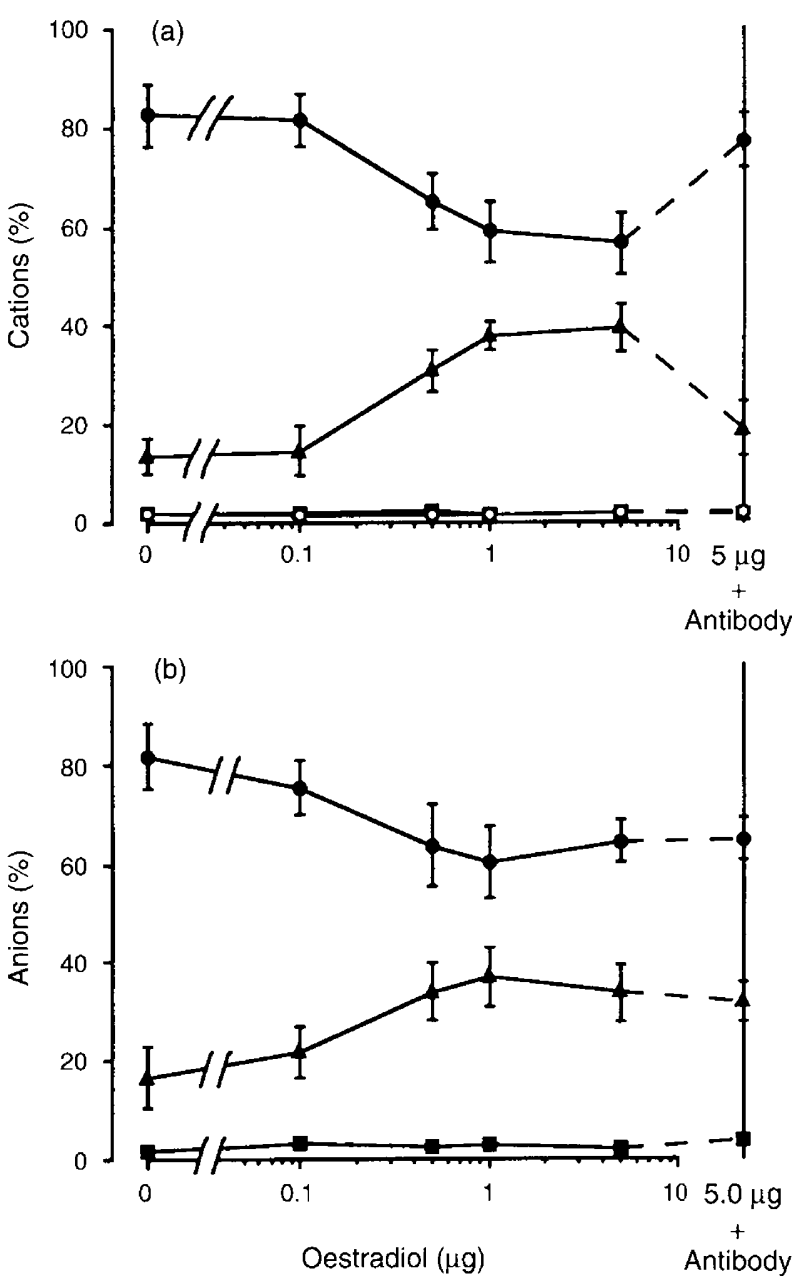

Fig. 2. The effect of oestradiol on the electrolyte composition of uterine luminal fluid. Immature rats primed with 4 iu PMSG (i.p.; $n=3$ ) were given daily injections (s.c.) with $0.1,0.5,1.0$ or $5.0 \mu \mathrm{g}$ oestradiol from day 0 (day of mating) to day 2 of pregnancy. Rats $(n=3)$ treated with daily injections with $5.0 \mu \mathrm{g}$ oestradiol were infused (s.c.) with anti-IGF-I antibody from day 1 to day 3 . Uterine luminal fluid was collected on day 3 of pregnancy. The electrolyte composition is presented as a percentage of each component the mean and $95 \%$ confidence limit) to the total (a) cations or (b) anions. (a) $\bullet, \mathrm{Na}^{+} ; \mathbf{\Lambda}, \mathrm{K}^{+} ; \mathbf{\square}, \mathrm{Ca}^{2+} ; 0, \mathrm{Mg}^{2+}$. (b) $\bullet, \mathrm{Cl}^{-} ; \mathbf{\Lambda}, \mathrm{HCO}_{3}{ }^{-}$; a, $\mathrm{HPO}_{4}{ }^{2-}$

\section{Discussion}

The present study provided evidence that uterine growth factors may be involved in the regulation of the uterine electrolyte environment, and suggested that hyperoestrogenaemia caused by superovulation may alter the uterine electrolyte environment, at least in part, through increased IGF-I action. Although some observations were made under a pathophysiological condition, namely superovulation, our study suggests strongly the presence of an endocrine or paracrine regulation on the uterine electrolyte environment during preimplantation embryonic development.

Recent evidence suggests that ovarian steroid hormones exert many of their actions through growth factors and cytokines in the uterus. IGF-I is one of these growth factors 

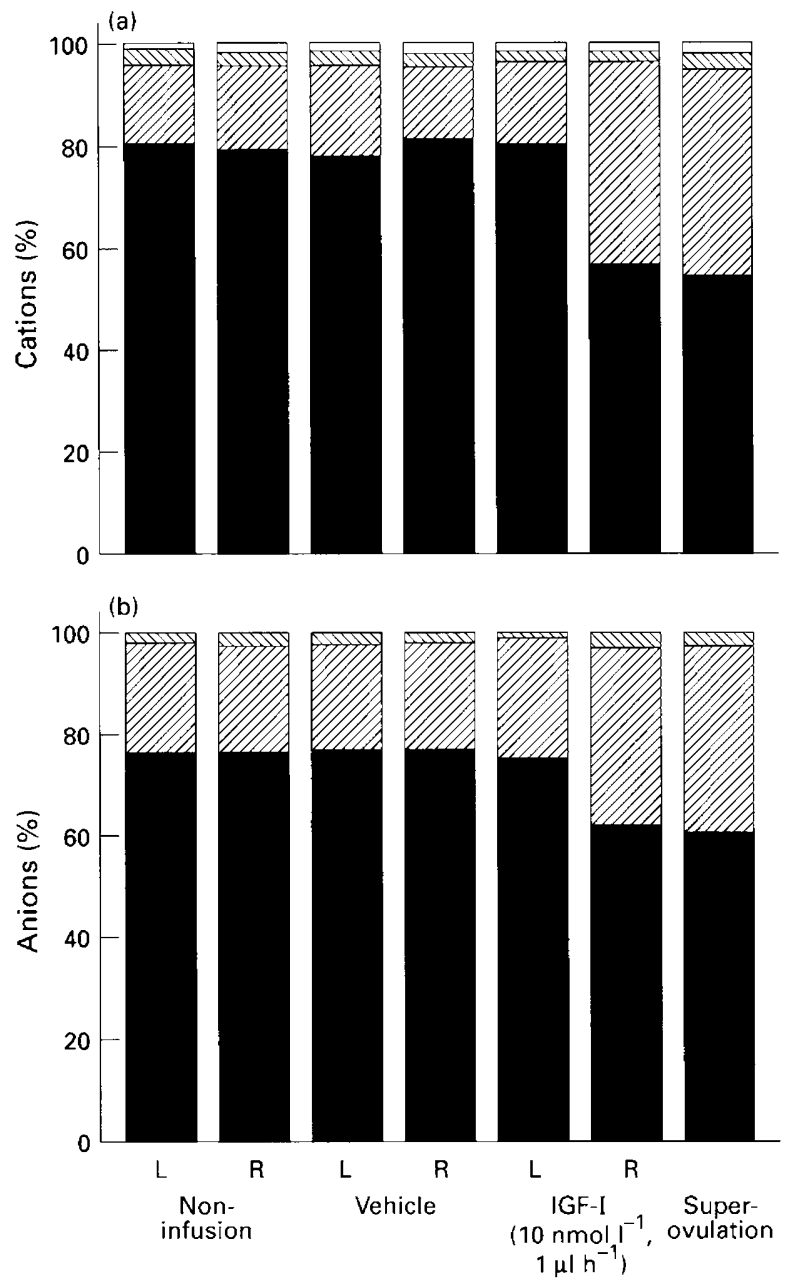

Fig. 3. The effect of insulin-like growth factor I (IGF-I) infusion on the electrolyte composition of uterine luminal fluid. Adult rats $(n=5)$ were mated at oestrus, infused with human recombinant insulin-like growth factor I (IGF-I, $10 \mathrm{nmol} \mathrm{I} \mathrm{I}^{-1}, 1 \mu \mathrm{h}^{-1}$ ) from day 1 to day 3 of pregnancy. Uterine luminal fluid was collected on day 3 . The electrolyte composition is presented as the mean percentage of each component to the total (a) cations or (b) anions. (a) $\mathbf{\square}, \mathrm{Na}^{+} ; \square, \mathrm{K}^{+}$,

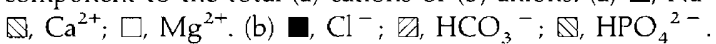

and its synthesis is primarily regulated by oestrogen in the uterus (Murphy et al., 1987; Murphy and Ghahary, 1990). In superovulated immature rats, PMSG injected to induce superovulation causes hyperoestrogenaemia that in turn increases IGF-I action in the uterus (Miller and Armstrong, 1981; Katagiri et al., 1996). The enhanced IGF-I action caused by hyperoestrogenaemia appears to be a mechanism by which superovulation alters the electrolyte composition of uterine luminal fluid. IGF-I infusion altered the electrolyte composition, as is observed after superovulation and oestradiol ( $\mathrm{I}$ and $5 \mu \mathrm{g}$ ) treatment, only in the infused horns. Alterations in cation composition after superovulation and oestradiol ( 1 and $5 \mu \mathrm{g}$ ) treatment were restored by anti-IGF-I antibody infusion to control concentrations, suggesting that exposure to high concentrations of IGF-I causes changes in cation composition. In contrast, the role for IGF-I in the regulation of anion composition is less clear. Although IGF-I infusion mimicked the
Table 1. Total cation content in the uterine luminal flushes from rats treated with pregnant mares' serum gonadotrophin (PMSG), oestradiol, and IGF-I

\begin{tabular}{|c|c|c|}
\hline Treatments & $\begin{array}{c}\text { Uterine } \\
\text { horn }\end{array}$ & $\begin{array}{l}\text { Total cation } \\
\text { concentration } \\
\left(\text { nmol } 1^{-1}\right)^{a}\end{array}$ \\
\hline \multicolumn{3}{|l|}{ PMSG (iu) } \\
\hline 4 & Both $^{b}$ & $1.33 \pm 0.30$ \\
\hline 10 & Both & $1.28 \pm 0.22$ \\
\hline 20 & Both & $1.34 \pm 0.26$ \\
\hline 40 (Superovulation) & Both & $2.52 \pm 0.29^{c}$ \\
\hline $40+$ IGF-I antibody ${ }^{\mathrm{d}}$ & Both & $2.18 \pm 0.32^{\mathrm{c}}$ \\
\hline \multicolumn{3}{|l|}{ Oestradiol $(\mu \mathrm{g})$} \\
\hline 0.1 & Both & $1.16 \pm 0.40$ \\
\hline 0.5 & Both & $1.59 \pm 0.34$ \\
\hline 1.0 & Both & $2.78 \pm 0.46^{c}$ \\
\hline 5.0 & Both & $2.31 \pm 0.44^{c}$ \\
\hline $5.0+$ IGF-I antibody ${ }^{d}$ & Both & $2.67 \pm 0.41^{\circ}$ \\
\hline \multicolumn{3}{|l|}{ Infusions $^{c}$} \\
\hline \multirow[t]{2}{*}{ Non-infusion } & Left & $1.21 \pm 0.21$ \\
\hline & Right & $1.22 \pm 0.18$ \\
\hline \multirow[t]{2}{*}{ Vehicle } & Left & $1.19 \pm 0.21$ \\
\hline & Right & $1.23 \pm 0.31$ \\
\hline \multirow[t]{2}{*}{ IGF-I } & Left & $1.23 \pm 0.33$ \\
\hline & Right & $1.31 \pm 0.26$ \\
\hline
\end{tabular}

"Values represent the means \pm s) for five rats, except for oestradiol groups, in which three rats were used.

buterine luminal fluid from the left and right horn in the same rat were combined.

'Total cation concentration is greater than that of the other groups $(P<0.01)$. dAnti-lGF-I antibody was systemically infused from day 1 to day 3 .

'Infusions were performed on the right uterine horn and the left horn was used as the control.

alterations in anion composition caused by superovulation, anti-IGF-I antibody failed to restore these alterations in anion composition. This, however, does not rule out a role for IGF-I in regulating concentrations of anions in uterine luminal fluid. Alterations in the anion composition of uterine luminal fluid may be regulated by multiple factors including IGF-I. Therefore, inhibition of IGF-I action alone may not restore the altered anion composition, caused by the superovulatory treatment. This is in direct contrast to the regulation of cation composition, in which IGF-I appears to play a major regulatory role.

It is unclear how IGF-I causes alterations in the electrolyte composition of uterine luminal fluid. A possible explanation is that disruption of the endometrial epithelial cells may be responsible for the increase in the $\mathrm{K}^{+}: \mathrm{Na}^{+}$ratio, since intracellular fluid has a greater $\mathrm{K}^{+}: \mathrm{Na}^{+}$ratio than extracellular fluid. This is supported by the presence of desquamated cellular debris in the uterine flushings from superovulated rats (Miller and Armstrong, 1981). However, disruption of the uterine luminal epithelial cells is unlikely to contribute significantly to the increase in the $\mathrm{K}^{+}: \mathrm{Na}^{+}$ratio observed in the present study: first, because a visible amount of cellular debris was observed in some of the uterine luminal flushes of the superovulation and IGF-I infusion groups but the amount of cellular debris was considerably less in the IGF-I group than that observed in the superovulation group, while comparable 
changes in $\mathrm{Na}^{+}$and $\mathrm{K}^{+}$concentrations were observed in the two groups, and second, because the concentrations of $\mathrm{HPO}_{4}{ }^{2-}$ were constant throughout these experiments. Since intracellular fluid contains high concentrations of inorganic phosphate, disruption of cells will result in an increase in $\mathrm{HPO}_{4}{ }^{2-}$ concentrations, which was not observed in this study. The mechanism by which IGF-I regulates uterine electrolyte environment remains to be determined.

Damage to the uterine luminal epithelium caused by flushing of the uterine luminal and consequent contamination of uterine luminal flushes by plasma and interstitial fluid has been described in mice (Martin, 1984; Milligan and Martin, 1984). It is not known whether the presumed contamination of uterine luminal flushes contributed to the observed alterations in the electrolyte composition in the present study. The larger size of the rat uterus compared with the mouse uterus may limit the damage to the uterine luminal epithelium caused by uterine flushing. The previous study suggests that the degree of contamination of uterine flushes, caused by flushing of the uterine lumen, depends on the degree of uterine closure (Milligan and Martin, 1984). Uterine closure is not yet apparent in the rat uterus on day 3 of pregnancy, the day of sample collection in the present study. Thus the presumed contamination caused by flushing of the uterine lumen may not be critical in the present study. However, the contamination of uterine flushes by plasma and interstitial fluid is still the potential source of artifact that may affect the interpretation of our data. Further studies that determine the degree of contamination of uterine flushes by plasma and interstitial fluid may be necessary.

Superovulation may also increase uterine luminal fluid volume. In general, the sum of the four cations that were examined in this study well represents total cation concentrations in body fluid and total anion concentrations are equivalent to those of cations. Since total electrolyte concentration in body fluid is closely maintained, an increase in total cation content in uterine luminal flushes by approximately twofold, observed in the present study in response to superovulation and oestradiol treatment, may be associated with a comparable increase in the volume of uterine luminal fluid. The increase in cation content and uterine wet mass of up to twofold observed after superovulation in immature rats (Miller and Armstrong, 1981) is consistent with the accumulation of fluid in the uterus and uterine lumen. In contrast, total cation content in the uterine luminal fluid of the IGF-I infusion and superovulation plus anti-IGF-I antibody groups was indistinguishable from that of the non-infusion group. These observations suggest that the presumed increase in the volume of uterine luminal fluid caused by superovulation is mediated by oestrogen. Oestrogen may regulate the fluid volume directly or, more likely, the oestrogen action is mediated by undetermined factors other than IGF-I.

The ratio of $\mathrm{Na}^{+}: \mathrm{K}^{+}$in the non-infusion and 4 iu PMSG control groups of the present study (5.2:1 and 6.0:1, respectively) is different from that observed in uterine flushes obtained on day 5 of pregnancy (1.4:1) (Setty et al., 1973). Differences in experimental design between the two studies, such as animal treatment or timing of sample collection, may affect the electrolyte composition. However, the unusually low $\mathrm{Na}^{+}: \mathrm{K}^{+}$ratio (1.4:I) in the previous study suggests that the difference in the method of uterine luminal fluid collection may be largely responsible for the difference in the ratio of the two cations. The previous experiment used deionized water $(0.5 \mathrm{ml}$ per horn), while the present study used isotonic solution $(0.25 \mathrm{ml}$ per horn). Use of a large volume of hypotonic solution may inevitably increase $\mathrm{K}^{+}$content by causing cell disruption during uterine luminal fluid collection.

Alterations in the electrolyte composition observed in the present study are characterized by a decrease in $\mathrm{Na}^{+}: \mathrm{K}^{+}$and $\mathrm{Cl}^{-}: \mathrm{HCO}_{3}{ }^{-}$ratios from 6.0:1 (control) to 1.3:1 (superovulation) and from 3.6:1 to 1.6:1, respectively, in the PMSG-treated immature rats. These alterations may have a significant effect on embryonic development. The influence of electrolyte environment on preimplantation embryonic development has been studied by using the in vitro culture system. High concentrations of $\mathrm{K}^{+}$in culture media reduce the rate of blastocyst formation in mice (Wiley, 1984; Lawitts and Biggers, 1991). Substitution of either $\mathrm{Na}^{+}$or $\mathrm{Cl}^{-}$in the embryo culture media reduced the rate of blastocoel expansion (Manejwala et al., 1989). Low concentrations of $\mathrm{NaCl}$ in the culture medium allow glutamine, a preferred energy substrate for early preimplantation embryos, to impair embryonic development (Chatot et al., 1989; Lawitts and Biggers, 1992). Thus, the decrease in $\mathrm{Na}^{+}: \mathrm{K}^{+}$and $\mathrm{Cl}^{-}: \mathrm{HCO}_{3}{ }^{-}$ratios appears to be detrimental to preimplantation embryonic development or at least blastocyst formation. This is consistent with the observation that uterine luminal fluid obtained from the superovulated rats or uterine luminal fluid from the uterus that was exposed high concentrations of IGF-I decreases the rate of blastocyst formation (Katagiri et al., 1996).

In summary, IGF-I may play a central role in the regulation of the uterine electrolyte environment, especially cations, during preimplantation embryonic development. Superovulatory or oestradiol treatment may alter the electrolyte composition of uterine luminal fluid by increasing IGF-I action in the uterus. The changes in the electrolyte composition of uterine luminal fluid may partially explain the detrimental effect of uterine luminal fluid on embryonic development after superovulation. Further studies are needed to provide better understanding of the mechanisms by which oestrogen and IGF-I regulate the electrolyte environment and to elucidate their physiological significance. For example, the present study examined the effect of oestradiol in PMSG-primed immature rats in order to understand the effect of hyperoestrogenaemia in an immature rat superovulation model. Although the normality of pregnancies in PMSG-primed immature rats has been established (Nuti et al., 1975), confirmation of our findings that includes the effect of oestrogen on electrolyte composition by using non-gonadotrophin primed pregnant rats may be necessary before our findings can be generalized.

\section{References}

Chatot CL, Ziomek CA, Bavister BD, Lewis JL and Torres I (1989) An improved culture medium supports development of random-bred 1-cell mouse embryos in vitro. Journal of Reproduction and Fertility 86 679-688

Dietz AA and Bond EE (1982) Chloride, coulometric-amperometric method. In Standard Methods of Clinical Chemistry pp 149-152 Eds WR Faulkner and $S$ Meites. American Association for Clinical Chemistry, Washington, DC

Dumoulin JC, Evers JL, Michiels AH, Pieters MH, Bras M, Land JA and Geraedts JP (1993) Modulation of embryonic $\mathrm{Na}(+)-\mathrm{K}(+)$-ATPase activity and mouse 
preimplantation development in vitro in media containing high concentrations of potassium Molecular Reproduction and Development 36 320-327

Kao CY (1967) lonic basis of electrical activity in uterine smooth muscle. In Cellular Biology of the Uterus pp 386-448 Ed. RM Wynn. AppletonCentury-Crofts, New York

Katagiri S, Ho Yuen B and Moon YS (1996) The role for the uterine insulin-like growth factor $\mathrm{l}$ in early embryonic loss after superovulation in the rat Fertility and Sterility 65 426-436

Lawitts JA and Biggers JD (1991) Optimization of mouse embryo culture media using simplex methods Journal of Reproduction and Fertility 91 543-556

Lawitts JA and Biggers JD (1992) Joint effects of sodium chloride, glutamine, and glucose in mouse preimplantation embryo culture media Molecular Reproduction and Development 31 189-194

Lowry OH, Rosebrough NJ, Farr AL and Randall RJ (1951) Protein measurements with the folin-phenol reagent Journal of Biological Chemistry 193 265-275

Manejwala FM, Cragoe EJ and Schultz RM (1989) Blastocoel expansion in the preimplantation mouse embryo: role of extracellular sodium and chloride and possible apical routes of their entry Developmental Biology 133 210-220

Martin L (1984) On the source of uterine 'luminal fluid' proteins in the mouse Journal of Reproduction and Fertility 71 73-80

Miller BG and Armstrong DT (1981) Effects of a superovulatory dose of pregnant mare serum gonadotropin on ovarian function, serum estradiol, and progesterone levels and early embryo development in immature rats Biology of Reproduction 25 261-271

Milligan SR and Martin L (1984) The resistance of the mouse uterine lumen to flushing and possible contamination of samples by plasma and interstitial fluid Journal of Reproduction and Fertility 71 81-87

Moon YS, Yun YW and King WA (1990) Detrimental effects of superovulation Seminars in Reproductive Endocrinology 8 232-241

Murphy LJ and Ballejo G (1994) Growth factor and cytokine expression in the endometrium. In Molecular Biology of the Female Reproductive System pp 345-377 Ed. JK Findlay. Academic Press, San Diego, CA
Murphy LJ and Ghahary A (1990) Uterine insulin-like growth factor-1: regulation of expression and its role in estrogen-induced uterine proliferation Endocrine Review 11 443-453

Murphy LJ, Murphy LC and Friesen HG (1987) Estrogen induces insulin-like growth factor-I expression in the rat uterus Molecular Endocrinology 1 $445-450$

Nuti KM, Sridharan BN and Meyer RK (1975) Reproductive biology of PMSGprimed immature female rats Biology of Reproduction 13 38-44

Sanui H (1971) Activated oxygen ashing of biological specimens for the microdetermination of $\mathrm{Na}, \mathrm{K}, \mathrm{Mg}$, and $\mathrm{Ca}$ by atomic absorption spectrophotometry Analytical Biochemistry 42 21-28

Sanui H and Rubin H (1982) Atomic absorption measurement of cations in cultured cells. In lons, Cell Proliferation, and Cancer pp 41-52 Eds AL Boynton, WL McKeehan and JF Whitfield. Academic Press, New York

Schini SA and Bavister BD (1988) Two-cell block to development of cultured hamster embryos is caused by phosphate and glucose Biology of Reproduction 39 1183-1192

Seshagiri PB and Bavister BD (1991) Glucose and phosphate inhibit respiration and oxidative metabolism in cultured hamster eight-cell embryos: evidence for the 'crabtree effect' Molecular Reproduction and Development 30 105-111

Setty BS, Singh MM, Chowdhury SR and Kar AB (1973) The role of electrolytes of the endometrium and uterine fluid during delayed implantation in rats Journal of Endocrinology 59 46I-464

Van Winkle LJ (1977) Low $\mathrm{Na}^{+}$concentration: a factor contributing to diminished uptake and incorporation of amino acids by diapausing mouse blastocysts Joumal of Experimental Zoology 202 275-281

Van Winkle LJ, Campione AL and Webster DP (1983) Sodium ion concentrations in uterine flushings from 'implanting' and 'delayed implanting' mice Journal of Experimental Zoology 226 321-324

Wiley LM (1984) Cavitation in the mouse preimplantation embryo: $\mathrm{Na} / \mathrm{K}$ ATPase and the origin of nascent blastocoele fluid Developmental Biology $105 \quad 330-342$ 